\title{
Brazil tests GM mosquitoes to fight Dengue
}

\author{
Males with offspring-killing genes are replacing wild insects, say researchers.
}

Helen Mendes

11 April 2012

\section{RIO DE JANEIRO}

\section{An article from SciDev.Net}

Scientists in Brazil say an experiment to reduce populations of the dengue-carrying Aedes aegypti mosquito, by releasing millions of genetically modified (GM) insects into the wild, is working.

More than ten million modified male mosquitoes were released in the city of Juazeiro, a city of 288,000 people, over a period of time starting a year ago.

The results were released at a workshop in Rio last week (28-29 March), where the project's co-ordinator, Aldo Malavasi, said they were "very positive".

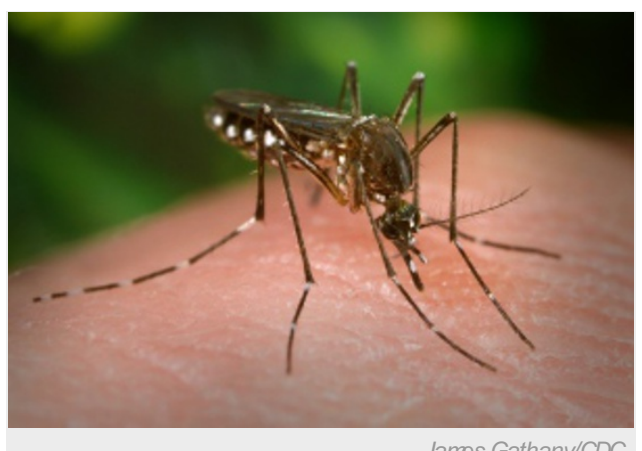

James Gathany/CDC

Engineered males might mean fewer female Aedes aegypti mosquitoes to spread Dengue fever.

"From samples collected in the field, 85 per cent of the eggs were transgenic, which means that the males released are overriding the wild population. This [should result] in the decrease of Aedes mosquitoes, and in the decrease of dengue transmission," he told SciDev.Net.

Malavasi is also the president of Moscamed — the Brazilian firm that produced the mosquitoes. The mosquitoes, which carry a gene which causes their offspring to die before reaching adulthood, were originally developed by the British firm Oxitec.

They have already been tested in Malaysia and the Cayman Islands, but this is believed to be the largest experiment in the wild to date.

"We developed technology to efficiently create the transgenic insects here [in Brazil], so we won't need to buy them from England in the future, reducing costs," Malavasi said.

The method has been approved by the Brazilian National Biosafety Technical Committee, and will be used in other Brazilian cities. Ultimately, it is hoped the GM mosquitoes will lead to the eradication of dengue in areas where insect translocation is low, and substantially reduced elsewhere.

Before releasing the mosquitoes, Malavasi said his team visited homes, schools and churches in Juazeiro to seek the permission of residents, and said nearly 90 per cent were in favour.

Margareth Capurro, a biologist from the University of São Paulo, confirmed residents support of the experiment.

"They were worried when they saw so many mosquitoes [being released], but we worked closely with them to explain the experiment," she told SciDev.Net. 
Mark Benedict, from the University of Perugia, Italy, said the results were promising. "The data indicates that the system is working as expected. We've seen no major issues with the way they are doing things, so I think it's very promising," he told SciDev.Net.

\section{SciDev Net}

Read more at SciDev.Net
Environmental advocates, including GeneWatch UK, have expressed concern over the potential of GM mosquitoes to survive and breed in the wild with unpredictable results.

Malavasi said he was confident the modified mosquitoes would be unable to produce viable offspring.

"But that doesn't mean that we are not careful. We are always running control tests," he said.

Malavasi said it would take time for lower Aedes populations to be reflected in lower dengue transmission rates, and said the researchers have yet to survey local communities to assess dengue incidence.

Nature | doi:10.1038/nature.2012.10426

This article was originally published by SciDev.net on 10 April 2012. 